\title{
Knowledge, Confidence, and Perception of Respiratory Therapists as Frontliners in Managing COVID-19 Cases - A Questionnaire Survey
}

\author{
Aathira Rajan, Madhura Reddy, Pratibha Todur, Saumy Johnson ${ }^{1}$ \\ Department of Respiratory Therapy, Manipal College of Health Professions, Manipal Academy of Higher Education, Manipal, Karnataka, India, ${ }^{1}$ Department of \\ Respiratory Therapy, Inaya Medical College, Riyadh, KSA
}

\section{Abstract}

Background: The deadly outbreak of coronavirus disease 2019(COVID-19) has imposed many challenges to health-care professionals (HCPs). The knowledge, confidence in performing clinical skills, and psychological impact have been studied among various HCP. Respiratory therapists (RTs) are the frontliners in handling critically ill COVID-19 victims. Although being an integral part, there are no studies on RTs in COVID-19. Hence, we aim to study the knowledge, confidence, and perception of RTs in managing COVID-19. Subjects and Methods: A cross-sectional, questionnaire-based survey conducted among RTs in India. The present study was conducted from July 15, 2020 , to August 1, 2020. Descriptive analysis was used to describe demographics, mean knowledge, confidence levels, perception, and psychological impact on RTs. Results: A total of 68 RTs responded with a response rate of $70.8 \%$. Of them, $60 \%$ (41) had good knowledge, 96\% (65) had higher confidence in performing required clinical skills, 98.5\% (67) had a perception that RTs plays an essential role in COVID-19 care, and 98.5\% (67) had a negative psychological impact. Reliability of the questionnaire was found to be in acceptable range. Conclusions: This study found that RTs in general had good knowledge and higher level confidence in performing procedure related to COVID-19. RTs perceive that the role of RT in COVID-19 is important.

Keywords: Confidence, COVID-19, knowledge, online survey, perception, respiratory therapists

\section{INTRODUCTION}

The coronavirus disease 2019 (COVID-19) caused by "Severe Acute Respiratory Syndrome Coronavirus 2" (SARS-CoV-2) started in Wuhan, China. On March 11, 2020, the World Health Organization (WHO) declared COVID-19 as a pandemic disease. As per the weekly operational report of COVID-19 by the WHO published on November 6, 2020, there were 48,534,508 confirmed cases and at least 1,231,017 deaths worldwide. ${ }^{[1]}$ In India, the first case of COVID-19 was detected in Kerala on January 30, 2020, and the cases are steadily increasing, and at present, there 8,591,730 confirmed cases with 127,059 deaths. ${ }^{[2]}$

Health-care professionals (HCPs), including doctors, nurses, and respiratory therapists (RTs), are the frontliners in the care of critically ill COVID-19 patients. Rigorous training about the disease was given to all HCPs through online platform to increase their knowledge, awareness, and practice skills for better management of this disease. RTs are integral part of

\begin{tabular}{|l|l|}
\hline \multicolumn{2}{|c|}{ Access this article online } \\
\hline Quick Response Code: & Website: \\
\hline & www.ijrc.in \\
\hline
\end{tabular}

core team in managing COVID-19. RTs are called as "unsung heroes" in the COVID-19 pandemic by a US magazine..$^{[3]}$ The current pandemic has led to an increased awareness of RT profession in many parts of the world, and public health-care system has started recognizing the importance of RTs.

Majority of COVID-19 patients with respiratory symptoms progresses to pneumonia, severe pneumonia, acute respiratory distress syndrome, sepsis, and septic shock. Respiratory failure requiring oxygen support and/or mechanical ventilation is the

Address for correspondence: Dr. Pratibha Todur Department of Respiratory Therapy, Manipal College of Health Professions, Manipal Academy of Higher Education, Manipal, Karnataka, India. E-mail: pratibha.todur@manipal.edu

This is an open access journal, and articles are distributed under the terms of the Creative Commons Attribution-NonCommercial-ShareAlike 4.0 License, which allows others to remix, tweak, and build upon the work non-commercially, as long as appropriate credit is given and the new creations are licensed under the identical terms.

For reprints contact: WKHLRPMedknow_reprints@wolterskluwer.com

How to cite this article: Rajan A, Reddy M, Todur P, Johnson S. Knowledge, confidence, and perception of respiratory therapists as frontliners in managing COVID-19 cases - A questionnaire survey. Indian J Respir Care 2021;10:93-9.

Received: 16-11-2020 Revised: 12-12-2020 Accepted: 16-12-2020 Published: 31-01-2021 
characteristic feature of SARS CoV 2 infection. Care of the patient requires not only the equipment and facilities but also the expertise of a trained RT.

Knowledge of a disease greatly influences the attitude and practice of a HCP in the management of a disease. The current pandemic has led to overburden on HCP due to the shortage of trained personal which has caused a negative psychological impact. To evaluate this, several questionnaires based surveys on COVID-19 have been done among specific HCP such as doctors, nurses, and pharmacists. ${ }^{[4-6]}$ As per our knowledge, there are no studies done specifically among RTs. The aim of our study is to evaluate the RTs knowledge on COVID-19, confidence in performing a specific clinical skill desired in COVID-19 care, perception, and psychological stress levels of RT's while managing COVID-19.

\section{Subjects and Methods}

\section{Study design and approvals}

This was a cross-sectional, questionnaire study with snow ball sampling conducted from July 15, 2020, to August 1, 2020. The present study was approved by the Institutional Research Committee and Institutional Ethics Committee (IEC 389-2020) and registered in the Clinical Trial Registry of India (CTRI/2020/07/026444). Electronic informed consent was obtained from each participant before data collection. Participants were free to withdraw from the survey anytime without providing justification.

\section{Study participants}

The participants were the qualified (either diploma, graduate, or postgraduate) RTs working in India in different geographic locations. During the time of the study, the confirmed COVID-19 cases were steadily increasing in the country, and some states were spiking the records. RTs were identified in each region, and the online questionnaire was sent through E-mail/WhatsApp. On clicking the link, the participants were directed to informed consent, following which the participants were allowed to fill the questionnaire. The respondents were encouraged to roll out the links of survey to their contacts.

\section{Data collection tool}

A self-prepared questionnaire was used for the study. The questionnaire was expert validated, and further reliability was also studied. Following this, the questionnaire was converted to Google forms for data collection. The questionnaire had 35 questions dividing into following sections:

a. Demographic and work details: five multiple-choice questions (MCQs)

b. Knowledge of RTs (awareness of COVID-19, mode of transmission, precautionary measures, diagnosis, and clinical presentation of the disease) ten MCQ with one right answer

c. Confidence level of RTs in performing desired clinical skills (delivery of supplementary oxygen, setting up of invasive and non-invasive ventilation, the procedure of intubation and extubation, skills required for routine management of a ventilator patient, and assisting in emergency procedures): ten questions with five-point Likert score (1 - not at all, 2 - not really, 3 - undecided, 4 - somewhat, and 5 - very much)

d. Perception of RTs role in COVID-19 disease: five questions with a numeric score of $1=$ yes and $0=$ no.

Psychological impact of COVID-19 on RTs: five questions with a five-point Likert score (1 - not at all, 2 - not really, 3 - undecided, 4 -somewhat likely, and 5 - very much likely).

\section{Study variables}

- Independent variables: Demographic data such as gender, age, academic qualifications, and geographic location

- Dependent variables: Knowledge, confidence levels, and perceptions toward COVID-19.

\section{Operational definitions Knowledge on COVID-19}

The RT's total knowledge score in COVID-19 was between 0 and $10(0=$ no correct answer and 10 all correct answers $)$.

\begin{tabular}{|c|c|}
\hline Parameter & $n(\%)$ \\
\hline \multicolumn{2}{|l|}{ Gender, $n(\%)$} \\
\hline Male & $28(41)$ \\
\hline Female & $40(59)$ \\
\hline \multicolumn{2}{|l|}{ Qualification, $n(\%)$} \\
\hline Diploma & $2(3)$ \\
\hline Undergraduate in RT & $58(85)$ \\
\hline Postgraduate in RT & $8(12)$ \\
\hline \multicolumn{2}{|l|}{ Geographic location (within India), $n(\%)$} \\
\hline Bangalore & $9(13)$ \\
\hline Chennai & $6(9)$ \\
\hline Coimbatore & $10(15)$ \\
\hline Kerala & $16(24)$ \\
\hline Mangalore & $3(4)$ \\
\hline Manipal & $16(24)$ \\
\hline Mumbai & $2(3)$ \\
\hline North India & $1(1)$ \\
\hline Hyderabad & $5(7)$ \\
\hline \multicolumn{2}{|l|}{ Area of work, $n(\%)$} \\
\hline ICUs & $63(93)$ \\
\hline PFT labs & $3(4)$ \\
\hline Others (rehabilitation units, homecare, and sleep study) & $2(3)$ \\
\hline \multicolumn{2}{|l|}{ Years of experience, $n(\%)$} \\
\hline $0-2$ & $47(69)$ \\
\hline $2-5$ & $15(22)$ \\
\hline $5-7$ & $2(3)$ \\
\hline$>7$ & $4(6)$ \\
\hline \multicolumn{2}{|l|}{ Involved in COVID- 19 management, $n(\%)$} \\
\hline Yes & $59(87)$ \\
\hline No & $9(13)$ \\
\hline
\end{tabular}

RT: Respiratory therapy, PFT: Pulmonary function testing, ICUs: Intensive care units 
Figure 1a: Individual questions with Multiple Choice Responses used to assess knowledge. The right answer for each question is underlined

\begin{tabular}{|c|c|c|}
\hline No & Question & Multiple choices \\
\hline Q1 & The COVID-19 infection is caused by a virus called & $\begin{array}{l}\text { A. } 2019 \mathrm{NCoV} \\
\text { B. SARS CoV2 } \\
\text { C. SARS CoV } \\
\text { D. None }\end{array}$ \\
\hline Q2 & The mode of transmission of the virus is by & $\begin{array}{l}\text { A. Droplets } \\
\text { B. Contact with the contaminated surfaces } \\
\text { C. Fomites } \\
\text { D. All of the above }\end{array}$ \\
\hline Q3 & $\begin{array}{l}\text { The most common specimen used to diagnose suspected covid- } 19 \text { patients in } \\
\text { triage is? }\end{array}$ & $\begin{array}{l}\text { A. Nasopharyngeal swab } \\
\text { B. Blood specimen } \\
\text { C. Stool specimen } \\
\text { D. None }\end{array}$ \\
\hline Q4 & While treating COVID-19 positive patients. The health care workers must wear & $\begin{array}{l}\text { A. Surgical mask } \\
\text { B. Cloth mask } \\
\text { C. N95 mask } \\
\text { D. Trilayered mask }\end{array}$ \\
\hline Q5 & $\begin{array}{l}\text { Nasopharyngeal specimen collection of a suspect COVID-19 positive patients } \\
\text { must be performed in }\end{array}$ & $\begin{array}{l}\text { A. Negative pressure isolation } \\
\text { B. Positive pressure isolation } \\
\text { C. Intensive care unit } \\
\text { D. Any isolation room }\end{array}$ \\
\hline Q6 & Oxygen supplement for a COVID-19 patient can be given by & $\begin{array}{l}\text { A. Nasal cannula } \\
\text { B. Nonrebreathing mask } \\
\text { C. Both A and B } \\
\text { D. None of the above }\end{array}$ \\
\hline Q7 & COVID-19 infection can lead to & $\begin{array}{l}\text { A. ARDS } \\
\text { B. Sepsis } \\
\text { C. Myocarditis } \\
\text { D. All of the above }\end{array}$ \\
\hline Q8 & WHO has described COVID_19 infection as & $\begin{array}{l}\text { A. Endemic } \\
\text { B. Pandemic } \\
\text { C. Epidemic } \\
\text { D. Sporadic }\end{array}$ \\
\hline Q9 & Most common symptoms of COVID-19 infection is & $\begin{array}{l}\text { A. Fever, cough, myalgia } \\
\text { B. Headache, dizziness } \\
\text { C. Fever, diarrhea, hemoptysis } \\
\text { D. Nasal congestion, myalgia, headache }\end{array}$ \\
\hline a & The first Indian state to report COVID-19? & $\begin{array}{l}\text { A. Uttar Pradesh } \\
\text { B. Maharashtra } \\
\text { C. Madhya Pradesh } \\
\text { D. Kerala } \\
\end{array}$ \\
\hline
\end{tabular}

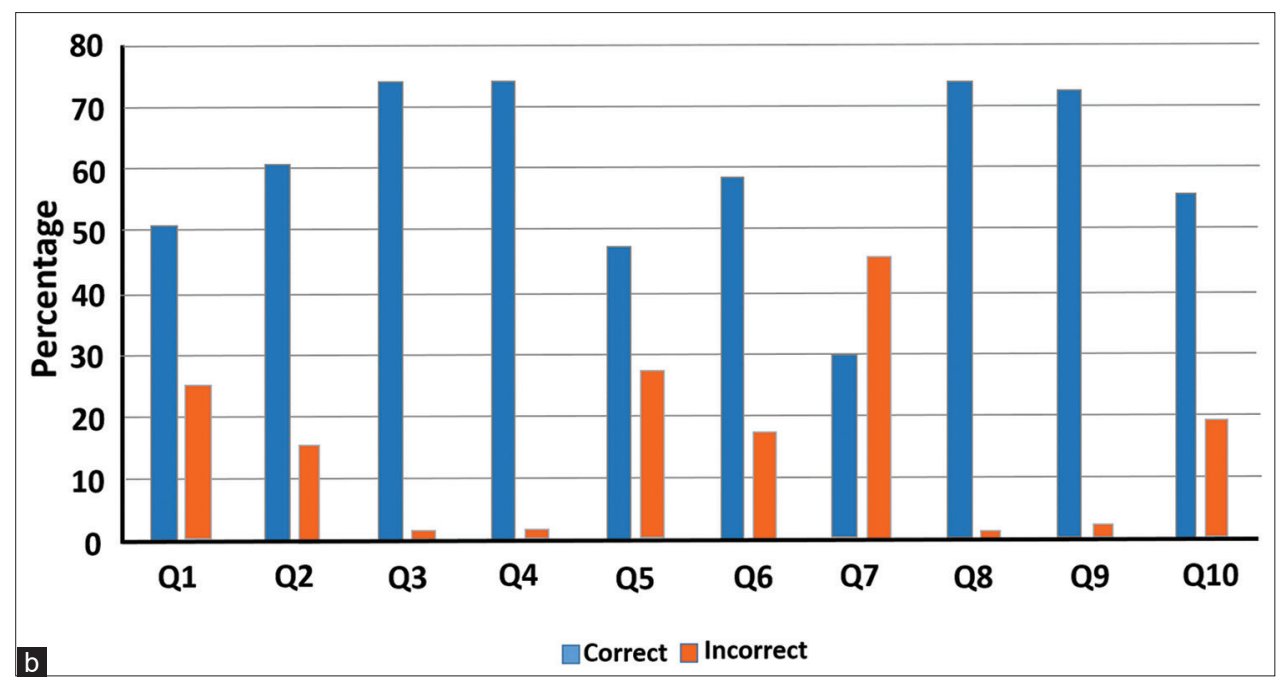

Figure 1: (a) Individual questions with multiple choice responses used to assess knowledge. The right answers for each question are underlined. (b) Response to each question in knowledge 
Rajan, et al.: Knowledge, confidence, and perception of RTs in COVID-19

\begin{tabular}{|c|c|c|c|c|c|}
\hline \multicolumn{6}{|c|}{ Confidence domain } \\
\hline \multirow[t]{2}{*}{ Questions Are you confident in } & \multicolumn{5}{|c|}{ Likert scoring, $\boldsymbol{n}(\%)$} \\
\hline & Not at all (1) & Not really (2) & Undecided (3) & Somewhat (4) & Very much (5) \\
\hline 1. Providing supplemental oxygen therapy & $1(1)$ & $3(4)$ & $4(6)$ & $14(21)$ & $46(68)$ \\
\hline 2. Setting up NIV & $2(3)$ & $4(6)$ & $6(9)$ & $16(24)$ & $40(59)$ \\
\hline 3. Preparing and assisting intubation & 0 & 0 & $2(3)$ & $11(16)$ & $55(81)$ \\
\hline 4. Setting up ventilator with airway adjuncts & 0 & 0 & 0 & $8(12)$ & $60(88)$ \\
\hline 5. Performing closed suction & 0 & $1(1)$ & $1(1)$ & $5(7)$ & $61(90)$ \\
\hline 6.Donning and doffing of PPE & 0 & 0 & $2(3)$ & $13(19)$ & $57(84)$ \\
\hline 7.Providing routine respiratory care & 0 & $1(1)$ & $1(1)$ & $17(25)$ & $49(72)$ \\
\hline 8. Collecting ET culture & $3(4)$ & $1(1)$ & $3(4)$ & $12(18)$ & $49(72)$ \\
\hline 9. Extubating the patient & $1(1)$ & 0 & $2(3)$ & $19(28)$ & $46(21)$ \\
\hline 10. Assisting airway-related procedure & 0 & $1(1)$ & $2(3)$ & $16(24)$ & $49(72)$ \\
\hline
\end{tabular}

NIV: Noninvasive ventilation, PPE: Personnel protective equipment, ET: Endotracheal tube

\section{Table 3: Psychological impact of coronavirus disease 2019 on respiratory therapies}

\begin{tabular}{|c|c|c|c|c|c|}
\hline \multicolumn{6}{|c|}{ Psychological impact } \\
\hline \multirow[t]{2}{*}{ Questions } & \multicolumn{5}{|c|}{ Likert scoring, $\boldsymbol{n}(\%)$} \\
\hline & $\begin{array}{l}\text { Not at } \\
\text { all (1) }\end{array}$ & $\begin{array}{c}\text { Not } \\
\text { really (2) }\end{array}$ & $\begin{array}{c}\text { Undecided } \\
\text { (3) }\end{array}$ & $\begin{array}{c}\text { Somewhat } \\
\text { (4) }\end{array}$ & $\begin{array}{c}\text { Very } \\
\text { much (5) }\end{array}$ \\
\hline $\begin{array}{l}\text { 1. What do you think are the likelihood of getting infected by a COVID-19 positive } \\
\text { case in your work area? }\end{array}$ & $2(3)$ & $6(9)$ & $24(35)$ & $26(38)$ & $10(15)$ \\
\hline 2. What do you think are the likelihood of surviving COVID-19 case if infected? & 0 & $1(1)$ & $19(28)$ & $25(37)$ & $23(34)$ \\
\hline $\begin{array}{l}\text { 3. Are you worried about your other family members getting infected by you with } \\
\text { COVID-19? }\end{array}$ & $2(3)$ & $9(13)$ & $2(3)$ & $9(13)$ & $46(68)$ \\
\hline 4. Do you think you will be easily infected by COVID-19 than other professionals? & 0 & $8(12)$ & $10(15)$ & $20(29)$ & $30(44)$ \\
\hline $\begin{array}{l}\text { 5. As a health-care professional do you experience psychological stress in managing } \\
\text { COVID-19 patients? }\end{array}$ & $3(4)$ & $21(31)$ & $2(3)$ & $18(27)$ & $24(35)$ \\
\hline
\end{tabular}

COVID-19: Coronavirus disease 2019

Scores were graded as follows: $<5$ - poor knowledge, 5-7 - moderate knowledge, and 8-10 - good knowledge.

\section{Confidence levels in performing skills required in} COVID-19 care

There were ten questions with a five-point Likert scale. The minimum scores were 10 (not at all confident in any skill) and maximum score was 50 (very much confident in all the skills). A mean score $>40$ (answering for somewhat or very much) was considered as higher confidence in performing the skills requiring in COVID-19 care.

\section{Respiratory therapist's perception on COVID-19 and psychological impact of COVID-19}

The questions to assess the perception of RTs role in treating a COVID-19 were based on five questions with numeric score of $1=$ yes and $0=$ no. The minimum and maximum scores were 0 (answering no to all questions) to 5 (answering yes to all questions). Mean score $>4$ considered the role of RT as important in managing COVID-19 cases.

\section{Psychological impact of COVID-19 on respiratory therapists}

It consisted five questions using five-point Likert score.
The mean score $>15$ (answering for undecided/regularly, somewhat/usually, and very much/always) was considered as a negative psychological impact on RT.

\section{Statistical analysis}

Continuous variables were reported in mean and standard deviation. Categorical variables (area of work, year of experience gender, qualification, region, and involved in COVID unit) were reported in $n(\%)$. The Likert scale scoring was expressed in $n(\%)$. Reliability of the questionnaire was tested using Cronbach's Alpha. Validity was assessed through correlation. The association between independent variables and dependent variables was assessed using the multivariate analysis. One-way ANOVA was done to study the difference between knowledge, confidence, and perception between genders Statistical software SPSS (IBM Corp. Released 2015. IBM SPSS Statistics for Windows, Version 23.0. Armonk, NY: IBM Corp) was used for the analysis. $P<0.05$ was considered statistically significant.

\section{RESULTS}

This was a cross-sectional, questionnaire-based study and a total of 68 RTs responded, yielding a response rate of $70.8 \%$. 


\begin{tabular}{lcc}
\hline $\begin{array}{l}\text { Table 4a: Correlation and } \boldsymbol{P} \text { values of questions in } \\
\text { knowledge domain }\end{array}$ \\
\hline Question number & Correlation & $\boldsymbol{P}$ \\
\hline Q1 & 0.291 & 0.013 \\
Q2 & 0.327 & 0.005 \\
Q3 & 0.096 & 0.424 \\
Q4 & 0.158 & 0.184 \\
Q5 & 0.431 & 0.000 \\
Q6 & 0.549 & 0.000 \\
Q7 & 0.520 & 0.000 \\
Q8 & 0.158 & 0.184 \\
Q9 & 0.273 & 0.020 \\
Q10 & 0.558 & 0.000 \\
\hline
\end{tabular}

\begin{tabular}{lcc}
\hline $\begin{array}{l}\text { Table 4b: Correlation and } \boldsymbol{P} \text { values of questions } \\
\text { assessing confidence levels }\end{array}$ \\
\hline \multicolumn{2}{l}{ Question number } & Correlation \\
\hline Q1 & 0.380 & $\boldsymbol{P}$ \\
Q2 & $0.293 *$ & 0.001 \\
Q3 & 0.568 & 0.012 \\
Q4 & 0.402 & 0.000 \\
Q5 & 0.665 & 0.000 \\
Q6 & 0.467 & 0.000 \\
Q7 & 0.736 & 0.000 \\
Q8 & 0.657 & 0.000 \\
Q9 & 0.549 & 0.000 \\
Q10 & 0.746 & 0.000 \\
*More significant & 0.000 \\
\hline
\end{tabular}

\begin{tabular}{lcc}
\hline $\begin{array}{l}\text { Table 4c: Correlation and } \boldsymbol{P} \text { values of questions assessing } \\
\text { perception }\end{array}$ \\
\hline Question number & Correlation & $\boldsymbol{P}$ \\
\hline Q1 & 0.599 & 0.000 \\
Q2 & 0.266 & 0.024 \\
Q3 & 0.468 & 0.000 \\
Q4 & 0.575 & 0.000 \\
Q5 & 0.468 & 0.000 \\
Q6 & 0.427 & 0.000 \\
Q7 & 0.233 & 0.049 \\
Q8 & 0.511 & 0.000 \\
Q9 & 0.642 & 0.000 \\
Q10 & 0.625 & 0.000 \\
\hline
\end{tabular}

Of them, more than half were females $(55.8 \%)$, qualified to bachelor's degree in respiratory therapy $(85 \%)$, working in ICU set up (93\%), had $<2$ years of experience $(69 \%)$, and majority of them were working in COVID-19 unit (87\%). The demographic and work details of the participants are summarized in Table 1.

\section{Knowledge about COVID-19}

The mean score obtained for the knowledge domain was 7.7 suggesting a good knowledge among RTs on COVID-19.

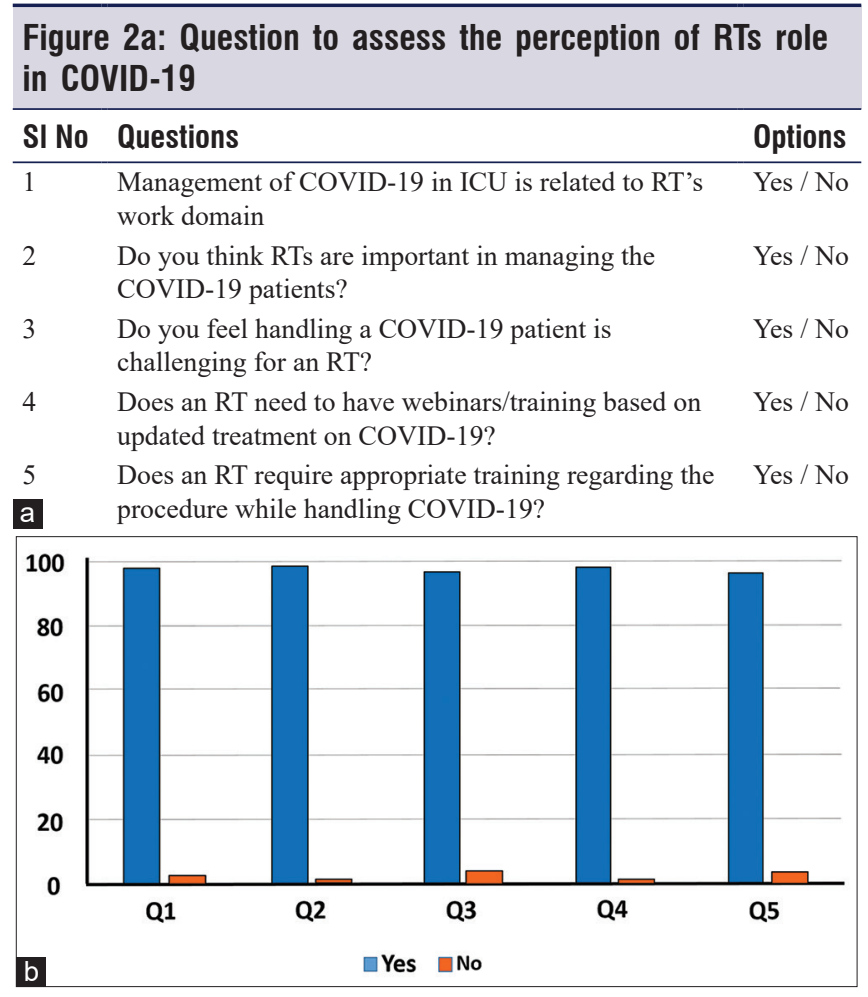

Figure 2: (a) Questions to assess the perception of respiratory therapist's role in COVID-19. (b) Response to each question in perception domain

About 1.5\% (1) had poor knowledge, 38\% (9) had moderate knowledge, and 60\% (41) had good knowledge about COVID-19. The questions of the knowledge domain are provided in Figure 1a. The individual analysis for each question is reported, as shown in bar graph Figure $1 \mathrm{~b}$.

\section{Confidence levels of respiratory therapists in performing a desired skill}

It was observed that $96 \%$ (65) were highly confident in performing all the desired skills related to respiratory care on COVID-19 patients. Detailed findings are summarized in Table 2.

\section{Perception on the role of respiratory therapist in COVID-19 care}

The present study found that $98.5 \%$ of the participants felt that the role of RTs in managing COVID-19 cases is important. Individual questions to access the perception of RT are depicted in Figure 2a. The response to each is summarized in Figure 2b.

\section{Psychological impact of COVID-19 on respiratory therapists}

About $98.5 \%$ (67) of RTs had a negative psychological impact due to the pandemic. The details are summarized in Table 3.

Validity was assessed through correlation. All the three sections of the questions had good correlation, and there was a significant difference between the questions. Table $4 a-c$ shows the correlation of questions for each domain. Reliability test (Cronbach's alpha $\alpha$ ) showed $\alpha$ of 0.65 which is an acceptable reliability. Multivariate analysis showed that 
Rajan, et al.: Knowledge, confidence, and perception of RTs in COVID-19

there was a significant difference between the psychological component and the education level of the participants. There was a difference between the perceptions by the bachelor's/master's graduate versus the PG diploma holder. One-way ANOVA showed no difference in knowledge, confidence, and perception of RTs between males and females.

\section{Discussion}

As per our knowledge, this is the first study on RTs, assessing the knowledge, confidence, and perception on COVID-19 pandemic.

A total of 68 RTs responded to the questions. Three domains of RTs were assessed. The Knowledge domain showed that $42(62 \%)$ of RTs had good knowledge, $25(37 \%)$ of them had moderate to good knowledge about COVID-19. This was consistent with studies conducted on other health-care workers (nurses, pharmacists, and physicians) concerning knowledge about COVID-19 pandemic. ${ }^{[3-5]}$ We were unable to compare the knowledge level among RTs, as no previous studies were conducted. Contrary to this, a study conducted globally by Bhagavathula et al. found that healthcare workers had insufficient knowledge on COVID-19. ${ }^{[6]}$ This could be because the study was conducted at the beginning of the pandemic, and our study was conducted during the peak phase of the pandemic.

Our study found a higher confidence level 65 (96\%) among RTs in performing clinical skills required for managing a COVID-19 case. Skills such as setting up ventilator and airway adjuncts, preparing and assisting intubation, performing closed suction had a score of more than $80 \%$ suggesting higher confidence in these areas. These findings confirm that most RTs in India have adequate training in independently managing the respiratory therapy skills required for care of COVID-19 in ICU. A cross sectional survey done in $\mathrm{Japan}^{[7]}$ and found that the confidence level in the management of COVID-19 among HCPs (doctors and other health-care workers) were very low, concluding that it could be due to the lack of latest information and absence of knowledge on how to protect themselves and their patients.

Perception of RTs toward the importance of their role in managing COVID-19 cases was found to be $98.5 \%$ (67) which indicated that almost all the study participants felt that RTs are an integral part of COVID-19 management. We also found that $98.5 \%$ (67) of study participants had an overall negative psychological impression toward the pandemic. The study participants were concerned about their family members getting infected by them and accounted for $80 \%$ mean score. Comparatively, the study participants had higher confidence in not being infected after using personal protective equipment. A systematic review found that anxiety, depression, and insomnia prevalence among health professionals during the COVID-19 outbreak were $23.2 \%, 22.8 \%$, and $38.9 \%$, respectively. ${ }^{[8]}$ Similar results were found in studies that assessed the psychological impact on other health-care workers in SARS CoV 2 infection. ${ }^{[9,10]} \mathrm{A}$ study done among health-care workers in Uganda had advised continued education among the health-care workers to improve the knowledge and avert the negative attitudes and promote preventive and therapeutic practices. ${ }^{[1]]}$

Reliability of the questionnaire that was developed by the researcher was tested and was found to be in acceptable reliability range. Cronbach's alpha is considered one of the most important tests where the test construction is involved. ${ }^{[12]}$ Alpha values are described as follows. Excellent (0.93-0.94), strong (0.91-0.93), reliable (0.84-0.90), robust (0.81), fairly high (0.76-0.95), high (0.73-0.95), good (0.71-0.91), relatively high (0.70-0.77), slightly low (0.68), reasonable (0.67-0.87), adequate $(0.64-0.85)$, moderate $(0.61-0.65)$, satisfactory $(0.58-0.97)$, acceptable $(0.45-0.98)$, sufficient $(0.45-0.96)$, not satisfactory $(0.4-0.55)$, and low $(0.11) \cdot{ }^{[13]}$

Validity is the degree to which a test measures what it is intended to measure. ${ }^{[14]}$ This is to measure basically the practical usefulness or to see how meaningful is the questionnaire. ${ }^{[15,16]}$ Validity of the questionnaire was good and could be used for further studies in the similar population. A larger study with the same questionnaire will give more insights to the validity and reliability of current questionnaire.

\section{Limitations}

This is a questionnaire-based survey and the responses depend on the participant's honesty and can be subjected to recall bias. Due to small sample size, statistical analysis for correlation could not be performed.

\section{Conclusions}

RTs have excellent clinical skills required during the management of COVID-19 patients in a high dependency or critical care unit. Being an integral part of a critical care unit, it is essential to assess any pandemic's knowledge and perception.

\section{Acknowledgment}

We would like to acknowledge and thank all RTs who have participated in the study across India and has helped in circulation the questionnaire.

\section{Financial support and sponsorship}

Nil.

\section{Conflicts of interest}

There are no conflicts of interest.

\section{RefERENCES}

1. WHO. Weekly Operational Update on COVID-19. World Health Organization; 2020. Available from: https://www.who.int/ publications $/ \mathrm{m} /$ item/weekly-operational-update-on-covid-21. [Last accessed 2020 Dec 16].

2. COVID-19 Tracker, India. Available from: http://www.covidindia.ord.

3. Available from: https://www.universityofcalifornia.edu/news/ respiratory-therapists-are-unsung-heroes-COVID-19-pandemic. [Last accessed 2020 Nov 10].

4. Saqlain M, Munir MM, Rehman SU, Gulzar A, Naz S, Ahmed Z, et al. Knowledge, attitude, practice and perceived barriers among healthcare workers regarding COVID-19: A cross-sectional survey from Pakistan. J Hosp Infect 2020;105:419-23. 
5. Al-Hanawi MK, Angawi K, Alshareef N, Qattan AMN, Helmy HZ, Abudawood Y, et al. Knowledge, attitude and practice toward COVID-19 among the public in the kingdom of saudi arabia: A cross-sectional study. Front Public Health 2020;8:217.

6. Ogolodom MP, Mbaba AN, Alazigha N, Erondu OF, Egbe NO, Golden I, et al. Knowledge, attitudes and fears of healthcare workers towards the corona virus disease (COVID-19) pandemic in South-South, Nigeria. Health Sci J 2020;Sp. Iss 1: 002.

7. Bhagavathula AS, Aldhaleei WA, Rahmani J, Khubchandani J. Knowledge, attitude, perceptions and practice towards COVID- 19: A systematic review and meta-analysis. medRxiv 2020.06.24.20138891; doi: https://doi.org/10.1101/2020.06.24.20138891 (preprint).

8. Kadoya Y, Zen K, Wakana N, Yanishi K, Senoo K, Nakanishi N, et al. Knowledge, perception, and level of confidence regarding COVID-19 care among healthcare workers involved in cardiovascular medicine: A web-based cross-sectional survey in Japan. J Cardiol 2020;S09145087(20)30276-8. Ahead of print.

9. Pappa S, Ntella V, Giannakas T, Giannakoulis VG, Papoutsi E, Katsaounou P. Prevalence of depression, anxiety, and insomnia among healthcare workers during the COVID-19 pandemic: A systematic review and meta-analysis. Brain Behav Immun 2020;88:901-7.
10. Giusti EM, Pedroli E, D'Aniello GE, Stramba Badiale C, Pietrabissa G, Manna C, et al. The Psychological Impact of the COVID-19 Outbreak on Health Professionals: A cross-sectional study. Front Psychol 2020;11:1684.

11. Olum R, Chekwech G, Wekha G, Nassozi DR, Bongomin F. Coronavirus disease-2019: Knowledge, attitude, and practices of health care workers at Makerere University Teaching Hospitals, Uganda. Front Public Health 2020;8:181.

12. Cortina JM. What is coefficient alpha? An examination of theory and applications. J Appl Psychol 1993;78:98-104.

13. Taber KS. The use of Cronbach's alpha when developing and reporting research instruments in science education. Res Sci Educ 2018;48:1273-96

14. Sapp SG, Jensen HH. Reliability and validity of nutrition knowledge and diet-health awareness tests developed from the 1989-1991 diet and health know-ledge surveys. J Nutr Educ 1997;29:63-72.

15. Wong KL, Ong SF, Kuek TY. Constructing a survey questionnaire to collect data on service quality of business academics. Eur J Soc Sci 2012;29:209-21.

16. Drost EA. Validity and reliability in social science research. Educ Res Perspect 2011;38:105-23. 